\title{
THE CHROMOSOMES OF CHRYSANTHEMUM,
}

\section{I: THE SPECIES}

\author{
G. J. DOWRICK \\ John Innes Horticultural Institution, \\ Bayfordbury, Hertford, Herts.
}

\section{INTRODUCTION}

Received 28.ix.5I

ThIs survey of Chrysanthemum species has been carried out in preparation for a study of new forms of the garden Chrysanthemum. Previous studies by Japanese workers were concerned with chromosome numbers and with species hybridisation (Shimotomai 1931 , 1932, $1937 a$ and $b, 1938$; Sugiura, 1937; Takemoto, 1939).

Some 140 species are recognised in the genus, of which $5^{6}$ have been examined cytologically. There is one basic number throughout $(x=9)$ but the numbers found in higher polyploids are no longer exact multiples of the basic number.

\section{MATERIALS AND METHODS}

The author wishes to thank the following for gifts of seeds or plants: the Directors of the Botanic Gardens at Glasnevin, Edinburgh, Oxford and Lausanne; Royal Botanic Gardens, Kew; The Royal Horticultural Society's Gardens, Wisley; Mr A. P. Balfour of Messrs Sutton, and Professor N. Shimotomai of Hiroshima University, Japan.

Chromosome counts of the species were made from root-tip squashes, using the Feulgen technique with mono-bromo-naphthalene pre-treatment (O'Mara, 1948). Acetic alcohol was used as fixative with hydrolysis for 15 minutes at $60^{\circ} \mathrm{C}$; normal time resulted in understaining. A Feulgen Squash technique was used for pollenmother-cells. Flowers were split up to let in the fixative and, for easier handling, anthers were not removed until after staining. Hydrolysis for 5 to 6 minutes suffices for pollen-mother-cells.

\section{SYSTEMATICS AND GEOGRAPHICAL DISTRIBUTION}

There are two main centres of distribution; one is in the Mediterranean area, particularly in Algeria and the Canary Islands, the other in China and Japan. The genus has spread throughout most of Europe and Asia. Several species, chiefly perennials, are used as decorative garden plants, the majority of these being of Oriental origin.

Most species have an outer ring of tongue-shaped ray florets surrounding a central mass of disc florets, while in others the ray florets are absent. Conversely horticultural selection has given rise to forms without disc florets. The majority of species are herbs; the rest are semishrubs.

Engler and Prantl divide the genus into eight sections, four containing annual and four perennial species. Six of these groups have been studied cytologically. Of the annuals, the sections Pinardia and 365 
Coleostephus have been studied. Ismelia and Ammanthus are still unexamined.

Four sections contain perennial herbs or shrubs. The Argyranthemum group, with three-angled fruits, contains i 2 to i 5 species with yellow or white ray florets. Ten of these originate in the Canary Islands and include $C$. frutescens, the common Marguerite, a semi-shrub with large white flowers often grown for decoration.

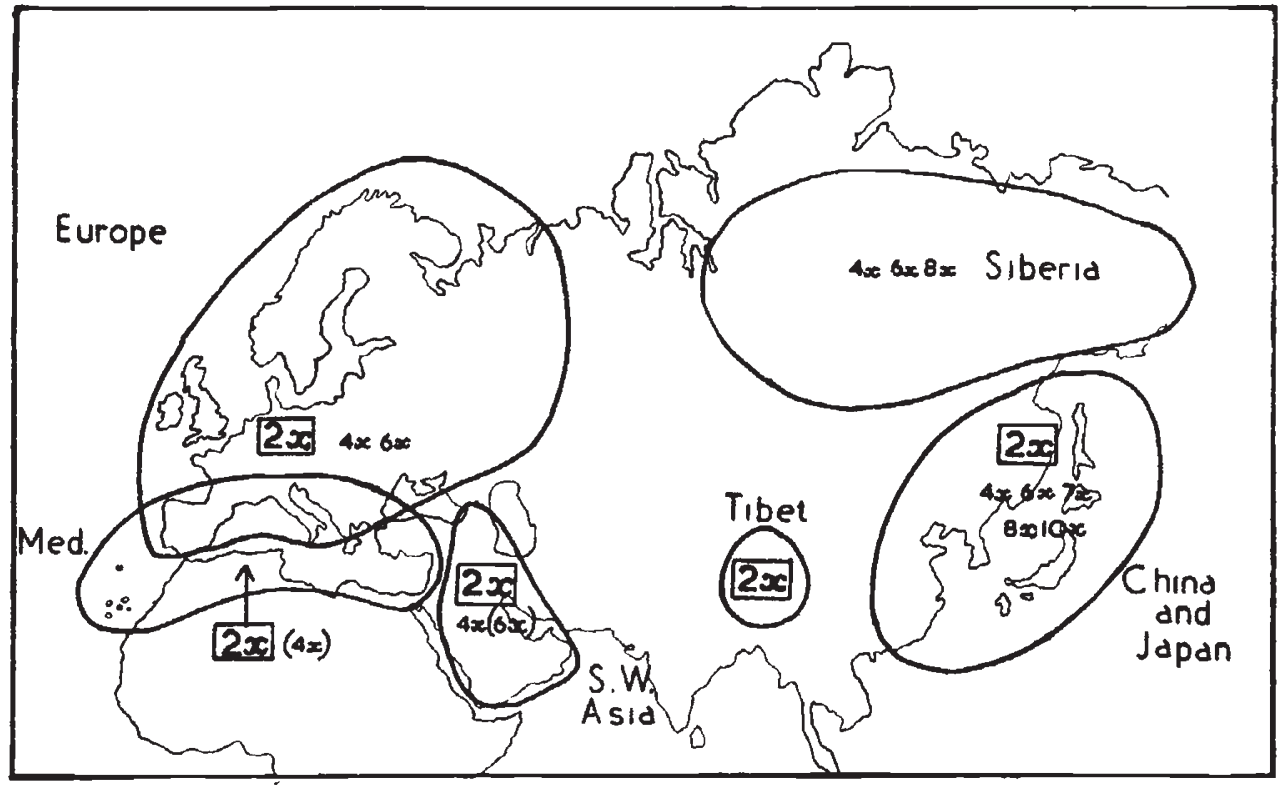

FIG. 1.-World distribution of Chrysanthemum species studied in relation to chromosome number. Most of the diploid species occur in the Mediterranean region, where the degree of polyploidy is much lower than in China and Japan. The European species are probably younger than the Oriental.

The three sections with 5 to ro ribbed fruits contain most species, as follows :

(i) Pyrethrum: 50 species with or without long yellow or white ray florets, and with long stalked single capitula giving typical $C$. coccineum, (Pyrethrum) flower heads. The most important is $C$. indicum, long cultivated as a garden plant in China and Japan. Its form is similar to many present day horticultural varieties. There are both "single" and " double" flower heads. This species has been chiefly concerned in the development of present day large-flowering garden Chrysanthemums.

(ii) Gymnocline: I4 species having discoid heads with very short yellow or white ray florets. Their centre is in the Caucasus and Dalmatia but a few species are Oriental.

(iii) Tanacetum: 50 species with short ray florets or none at all, spread throughout the Northern hemisphere. Seven are N. American, 12 are from the Himalayas and Tibet, while the remainder come from Europe and the Caucasus. 
TABLE I

Geographical Distribution in Relation to Chromosome Number

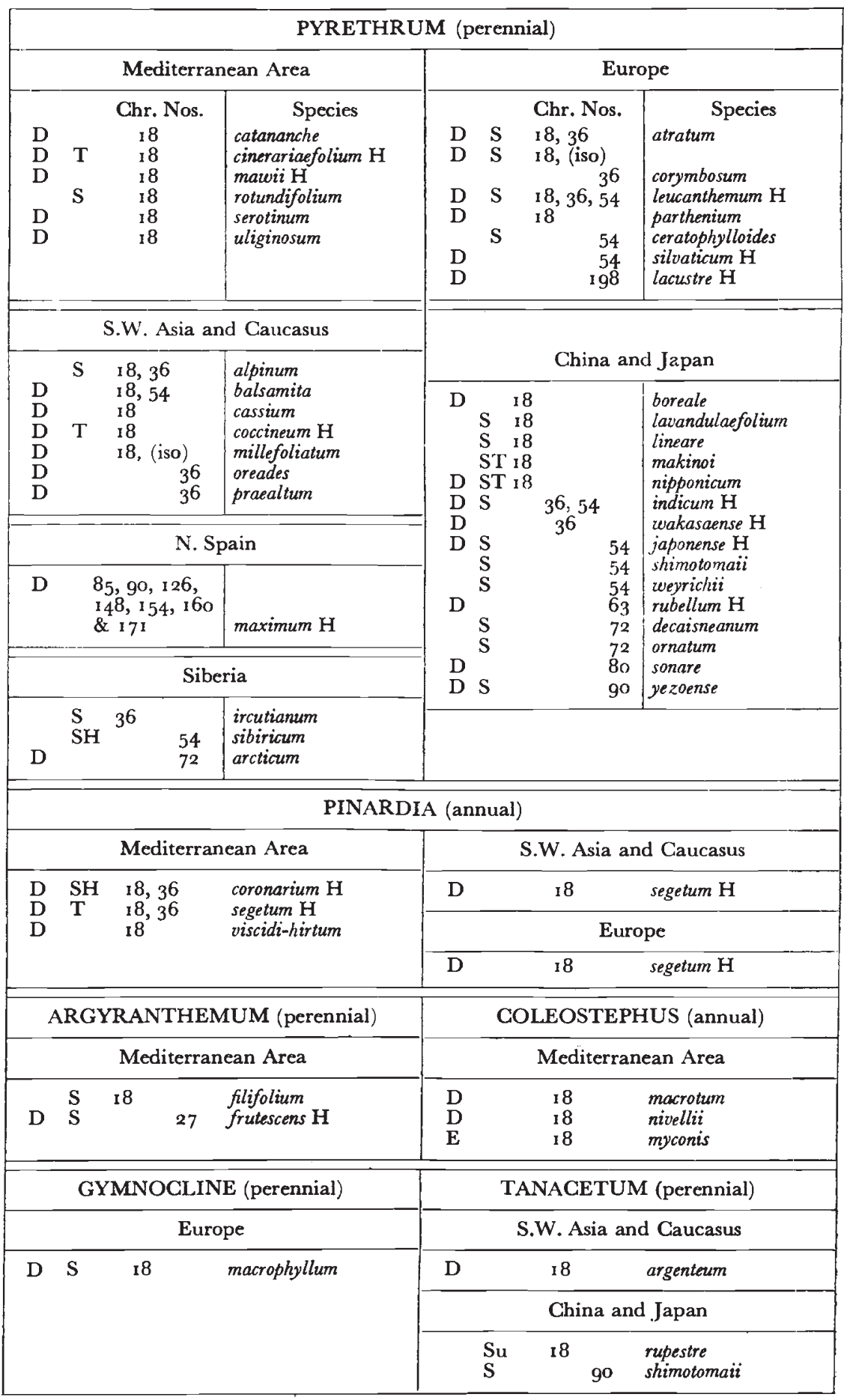

The species are grouped in their respective subgenera and according to geographical distribution. The letters before the chromosome numbers indicate the authors of the counts:
$\mathrm{D}=$ Dowrick
$\mathrm{S}=$ Shimotomai
$\mathrm{SH}=$ Shimotomai and Hara
$\mathrm{ST}=$ Shimotomai and
$\mathrm{SU}=$ Sugiura
Takemoto

The letter $\mathrm{H}$ behind the species name indicates it is of horticultural importance. 
Fig. I shows species distribution in relation to chromosome number. The majority of species, including all annuals, occur throughout the Mediterranean area with most towards the Western end.

Chromosome counts have now been made of 56 species of Chrysanthemum, as shown in table 1. Due to a Botanic Garden peculiarity most of the species collected in the past belong to the sub-section Pyrethrum and most of the species studied cytologically belong to this section.

Species situated around the Mediterranean are, with one exception, diploid or have diploid forms. The exception is C. maximum $(2 n=90)$, found in Northern Spain. The nearby area of the Caucasus and S.W. Asia similarly has only diploids, apart from $C$. oreades and $C$. praealtum which may of course have diploid forms, as yet unexamined.

The other main group, in China and Japan, has a much greater chromosomal range, from diploid to decaploid. It includes $C$. indicum and $C$. japonense, both hexaploid and both possibly involved in the development of garden Chrysanthemums. The degree of polyploidy in relation to geographical distribution is different from that in Paeonia (Stern, 1949), where the polyploids are found in the Mediterranean area and only diploids in Asia. Polyploids in Chrysanthemums rise to a much higher multiplication and the chromosomes diminish in size with their multiplication. They are therefore no doubt much older than the Paeonia tetraploids.

Polyploidy, in Chrysanthemum, is associated with increase in latitude. The diploids occuring mainly near the equator while, as in Rosa, only polyploids, e.g. C. arcticum, are found in Siberia and the Arctic.

The significant difference in the polyploidy found in the two main centres is no doubt due to difference in age of the species, those in China and Japan being very much older than the Mediterranean species. Only one species, $C$. indicum, has been found in China and Japan in different polyploid forms while in the Mediterranean and S.W. Asia area a number of such species exist suggesting that they are of recent origin and have not, as yet, become sufficiently differentiated to be considered as distinct species.

\section{CHROMOSOME NUMBER AND MORPHOLOGY}

Chromosome form and size vary little between or within species. In many cases the centromeres are all median or nearly so, as $C$. frutescens (fig. 2).

The species show a polyploid series between $2 \mathrm{x}-22 \mathrm{x}$ types.

Between the species of any one polyploid group there is little difference in chromosome size. Thus in diploid species, the chromosome size ranges from $6-8 \mu$. There is a gradual size diminution through the polyploid series to $C$. lacustre $(2 n=198)$ whose average chromosome size is under $3 \mu$. C. sonare $(2 n=80)$ has its largest chromosome $4 \mu$ long, with the majority being about $3.5 \mu$. 

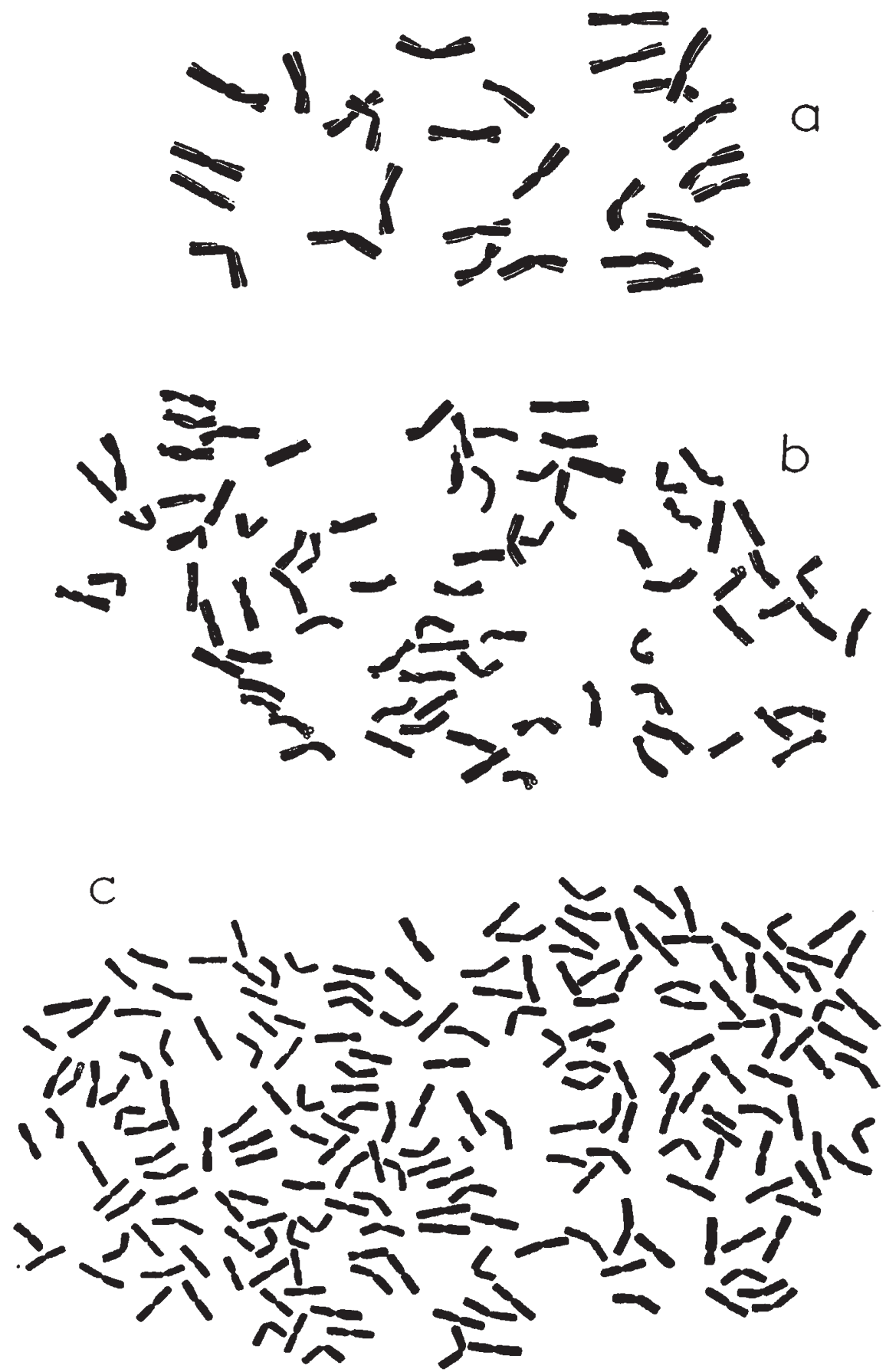

Fig. 2.-Somatic chromosome complement of (a) C. frutescens, $2 n=27$; (b) C. sonare, $2 n=80$ and (c) C. lacustre, $2 n=19^{8}$. Two small chromosomes with subterminal centromeres are contained in this complement. There is diminution in chromosome size with increase in the degree of polyploidy. 


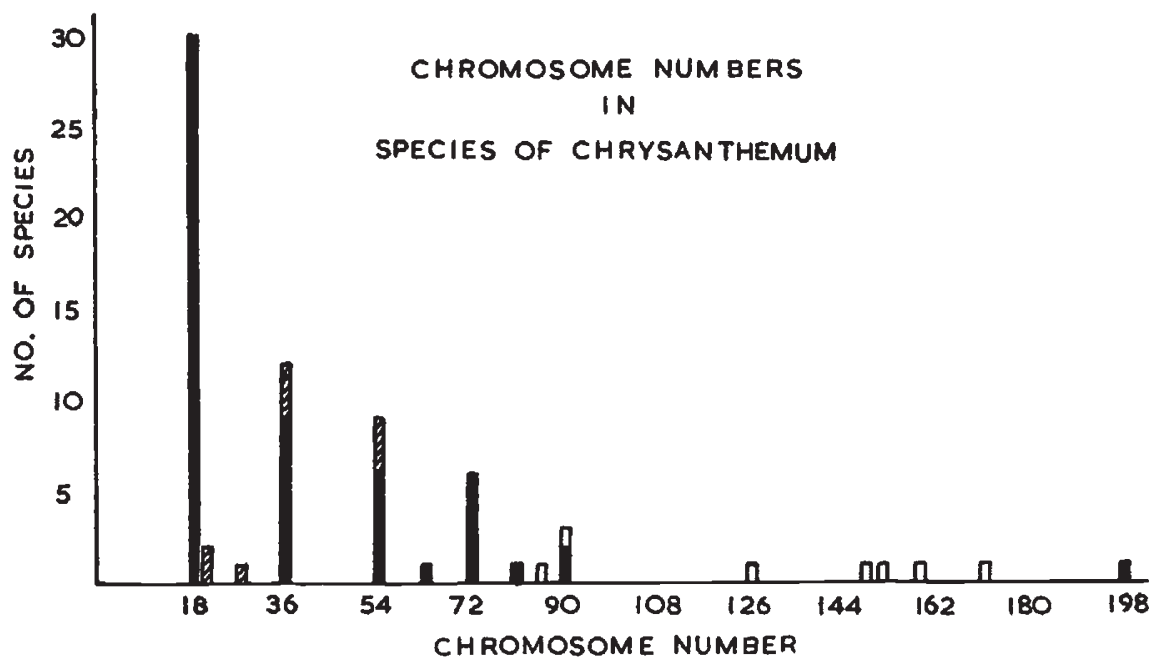

FrG. 3.- Graph of chromosome distribution in species of Chrysanthemum. The numbers marked by diagonal lines represent higher polyploid forms of other species. The white numbers between $2 n=85^{-1} 7$ r represent counts obtained from different plants of $C$. maximum.

C. maximum originates in the Pyrenees, with a chromosome number of about 90 . In garden forms the chromosome number varies from 85 to I 71. Counts have been made from 7 different plants and these yielded seven different numbers:

$2 n=85,90,126,148,154, \mathrm{I} 60$ and $\mathrm{I} 7 \mathrm{I}$.

This species, from which Burbank raised the "Shasta Daisy", has long white ray florets and is grown under such names as "Horace Reed", " Ester Reed", etc. It is probable that under cultivation a form with double the chromosome number of the original decaploid was produced, and used for breeding. Crosses between these two extremes of chromosome number would occur and give rise to a series of somatic numbers between 90 and $\mathrm{r} 80$.

The plant with 85 has probably arisen from one with 90 chromosomes by loss. The loss does not, in this case, have any great phenotypic effect.

In seven other species, forms are found with different degrees of polyploidy as follows:

\begin{tabular}{|c|c|}
\hline $\begin{array}{c}2 n=18,27 \\
\text { C. frutescens }\end{array}$ & \begin{tabular}{c} 
C. balsamita \\
\hline $\begin{array}{l}2 n=18,54 \\
\text { C. atratum } \\
\text { corymbosum } \\
\text { segetum }\end{array}$
\end{tabular} \\
$\begin{array}{c}\text { C. indicum } \\
\text { leucanthemum }\end{array}$ \\
\hline
\end{tabular}

In all these species there are no significant changes in form, apart from size and growth rate, with increase in the degree of polyploidy. They are not considered to be separate species. 


\section{ACCESSORY CHROMOSOMES}

In three species there are atypical chromosomes. C. lacustre, $2 n=198$, has a pair of very short euchromatic chromosomes with sub-terminal centromeres, unlike any others found in the genus.

C. corymbosum var. poteriifolium and $C$. millefoliatum, two species very similar in vegetative characters, are normally diploid. Plants were found, however, with a small extra chromosome. There are only very slight differences between the somatic chromosomes of these species.

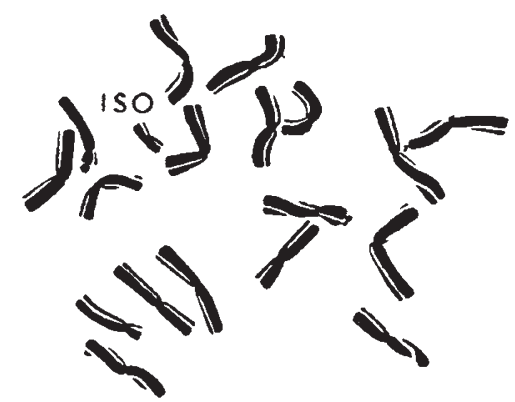

FIG. 4.-The somatic chromosomes of $(a)$ C. corymbosum var. poteriifolium.

$$
\times \quad \text { r, } 850
$$

The accessory chromosome appears to be identical in form and behaviour. It is an iso-chromosome. It is also heterochromatic, for it is visible in the resting nucleus when stained with the Feulgen technique. Although not in phase with the autosomes in its nucleic acid cycle, it does not lag behind them in its division. Its occurrence among plants was as follows:

$\begin{array}{lcc} & \text { With iso. } & \text { Without iso. } \\ \text { C. corymbosum } & 2 & 6 \\ \text { C. millefoliatum } & \text { I } & 2\end{array}$

That they are in fact iso-chromosomes with two homologous arms is shown during meiosis. At M I 9 bivalents are formed by the autosomes while the two arms of the accessory chromosome usually pair with each other to form a ring. The accessory chromosomes never pair with the normal set.

Normally the iso-chromosome divides at A I and lags on the metaphase plate during the second division. In one A I separation in $C$. millefoliatum, however, it was seen to misdivide, producing two telocentric chromosomes as in Secale and Campanula. In Secale the standard fragment chromosome of Müntzing (sf) undergoes similar misdivisions giving rise to both small and large telocentric chromosomes. Each of these by secondary misdivision of the centromere can give rise to their corresponding iso-chromosomes. These iso fragments have been seen to misdivide, as in the two species of Chrysanthemum. If these supernumeraries survive, no doubt, telocentric chromosomes will arise from them. 


\section{$\$ 00009000 \cdot$}

$-1 p(000040$

a

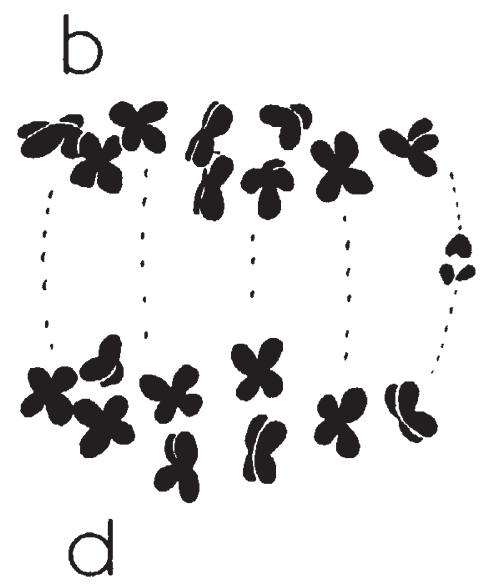

Frg. 5.-C. millefoliatum. (a) and (b) M I; $(c)$ and $(d) \mathrm{A} \mathrm{I}$.

(c) shows the normal type of A I found;

(d) shows the abnormal division with the formation of two telocentric chromosomes.

$\times \mathbf{r}, \mathbf{r g o}$

The accessory chromosome has little or no effect on the appearance of the plant.

\section{MEIOSIS}

Most stages of meiosis can be found within the same anther, but two anthers of a flower may be quite out of phase with one another. Anthers of polyploids tend to be larger at meiosis than those of diploids.

\section{(a) Diploid species}

Throughout the genus meiosis is regular except in $C$. atratum (which will be described later). In all diploid species 9 bivalents are formed regularly with an average chiasma frequency of $1 \cdot 5$. The chiasmata are normally terminal (Fig. 6). At M I the centromeres are pulled out towards the poles (plate I and fig. 6).

\section{(b) Triploid species}

$C$. frutescens is the only triploid studied. The number of univalents observed at meiosis varied between 3 and 7. In most divisions a chain of four was found at M I. Associations of more than four chromosomes were not observed, due possibly to the low chiasmata frequency. The univalents divide at either the first or second division and are lost at both divisions.

There are from $0-4$ micronuclei in young pollen. Pollen grains vary in size; the majority are haploid, or nearly so, while a few have higher 

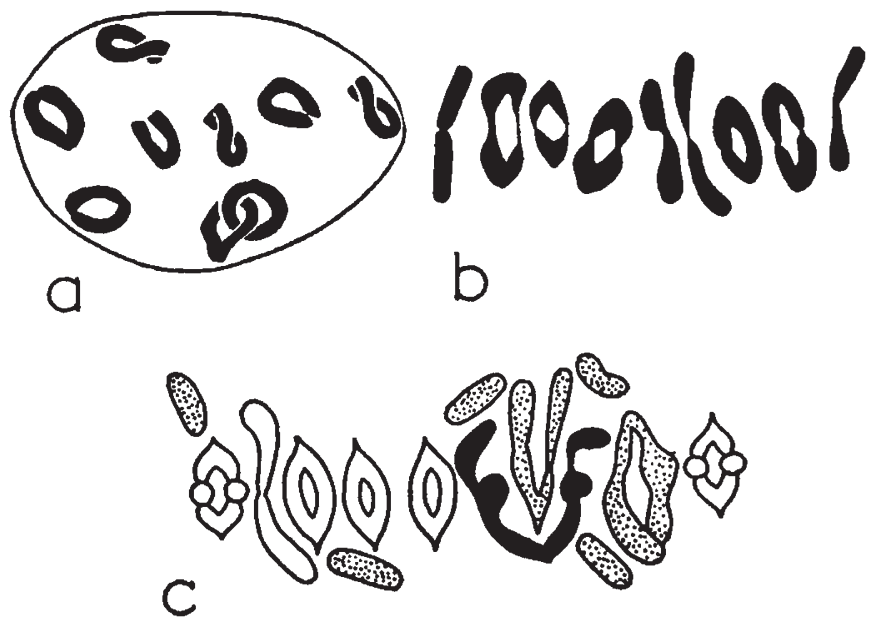

Fig. 6. - (a) Diakinesis in C. macrotum, $2 n=18$ with interlocking bivalents; (b) M I in C. coronarium, $2 n=18 ;(c) \mathrm{MI}$ in $C$. frutescens, $2 n=27$.

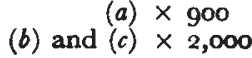

numbers. Fig. 7 shows the radii of mature grains and the four peaks are, no doubt, due to grains with $\mathrm{x}, 2 \mathrm{x}, 3 \mathrm{x}$, and $6 \mathrm{x}$ chromosomes. The species exists only in its triploid form in this country. From its meiotic behaviour it appears to be autotriploid. The slightly smaller form found in the Canary Islands is fertile and probably diploid.

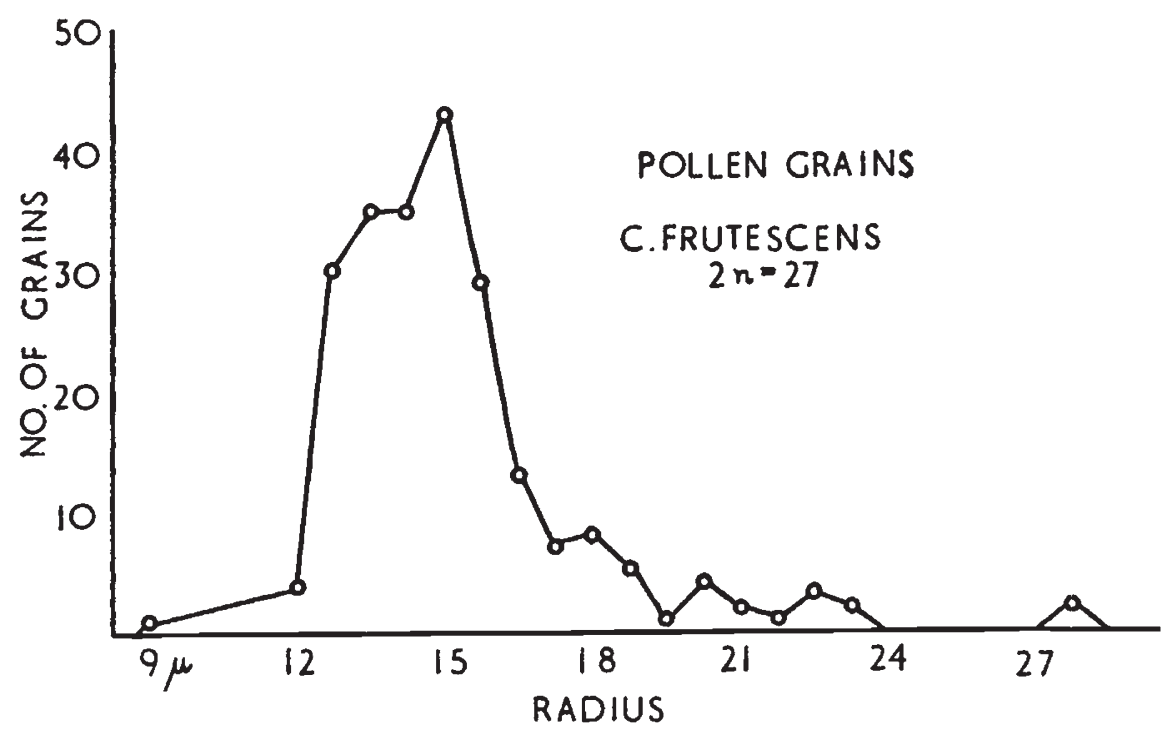

FIG. 7.-Graph of pollen grain size in C. frutescens, $2 n=27$. There is an absence of grains with lower chromosome numbers; they become eliminated more readily than the more diploid grains. 


\section{(c) Tetraploids and hexaploids}

In tetraploid and hexaploid species meiosis is necessarily more complex though even here some species behave like diploids. In C. silvaticum $(2 n=54)$ M I plates usually contain either 27 bivalents, 25 bivalents and 1 quadrivalent or 23 bivalents and 2 quadrivalents. The occurrence of trivalents and univalents is rare.

A I cells have been found with 36 chromosomes at each pole in C. leucanthemum the "Ox-Eye Daisy" $(2 n=36)$. This results in diad formation and pollen with the somatic chromosome number. It is a possible method by which the hexaploid form of this species has arisen, a process which may be related to the unusual meiosis of $C$. atratum.

\section{(d) Higher polyploids}

In one plant of C. maximum, where $2 n=160$ (plate $\mathrm{I}$ ) there are Io to 30 univalents at $\mathrm{MI}$; the remaining chromosomes are in groups of $2,3,4,5$ and 6 . Bridges are seen at A I when some univalents divide. The cytoplasm is small compared with the nucleus and hence there is little elimination of univalents at either first or second division. Mature pollen grains therefore show little variation in size, much less than in the triploid $C$. frutescens (fig. 8).

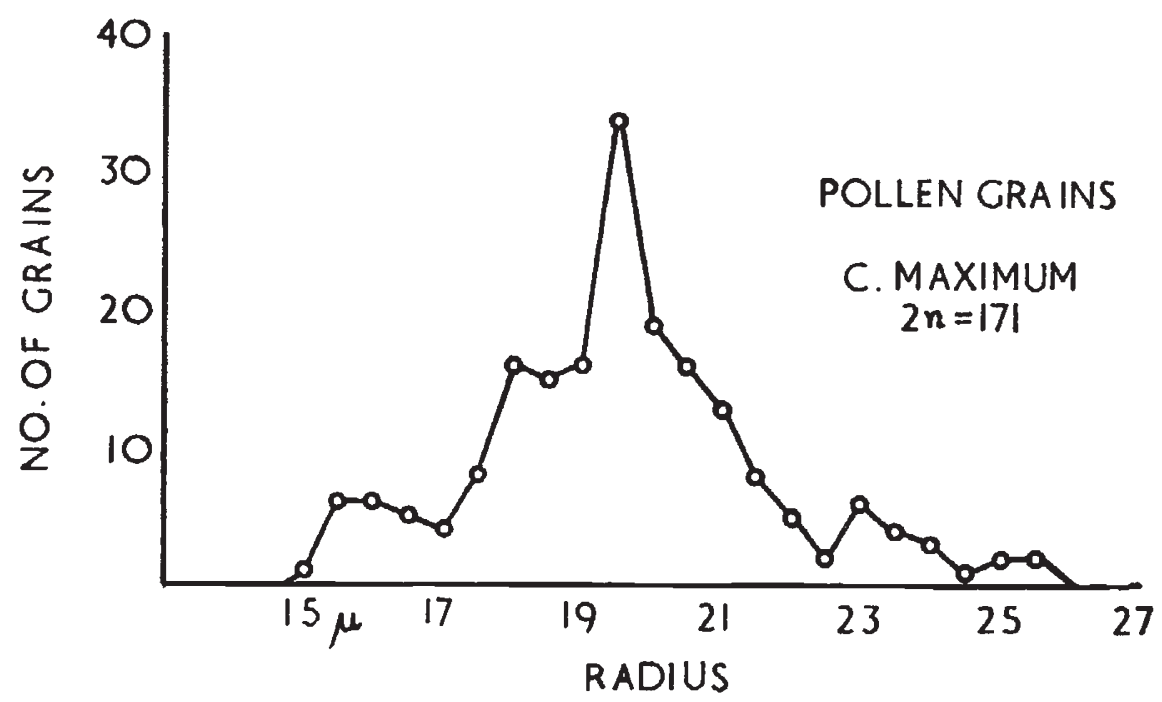

Fig. 8.-Pollen grain size in C. maximum, $2 n=160$. There is little variation in pollen grain size where the large chromosome number is concerned and is much less than in $C$. frutescens, $2 n=27$.

\section{SUMMARY}

I. Of the I 40 species in Chrysanthemum ${ }_{5}^{6}$ (in 6 of the 8 sections) have now been examined cytologically. The basic number throughout is 9 (list p. ooo). The chromosomes differ little amongst themselves. 


\section{Pl.ate}

(a) C. corymbosum $2 n=3 \bar{b}$

$\times 1,000$

(c) C. leucanthemum $2 n=54$

$\times 1,000$

(e) Diakinesis C. silvaticum $2 n=54$

$\times 1,000$ (b) C. marschalli $2 n=18$

$\times 1,000$

(d) C. corymbosum var. poteriifolium $2 n=\mathrm{I} 8+$ iso

$\times 1,000$

(f) M I C. coronarium

$\times 1,000$

(g) M I C. maximum $2 n-160$

(h) A I C. maximum 


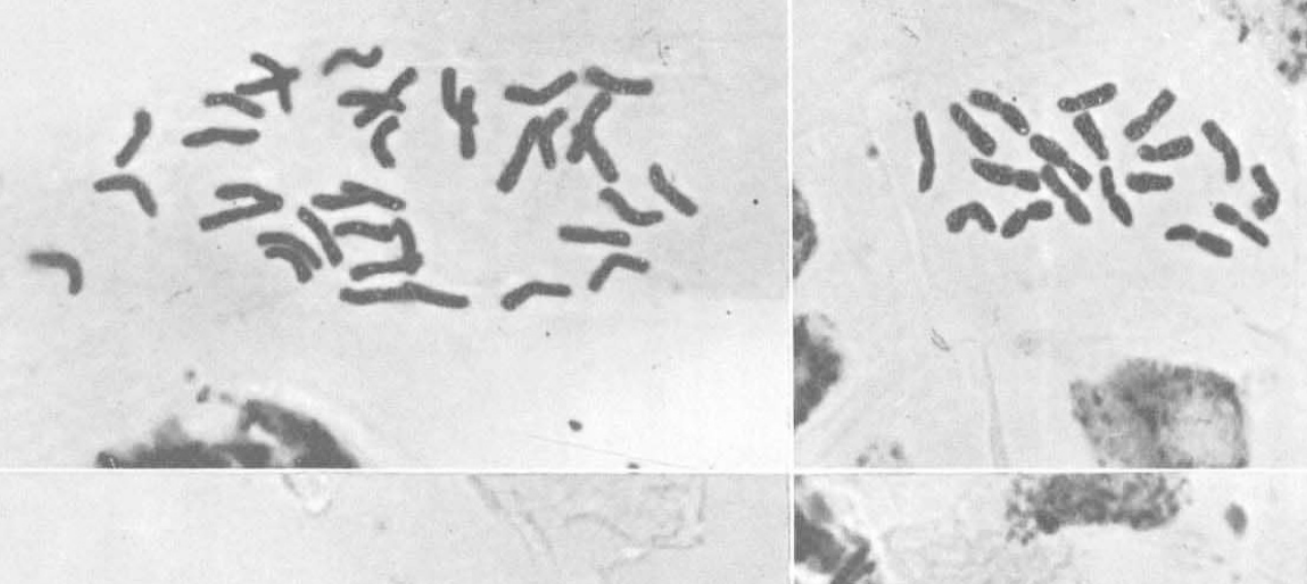

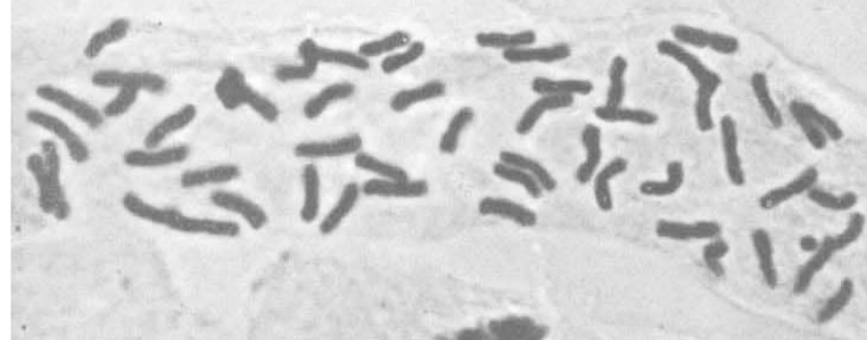

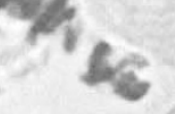

ब

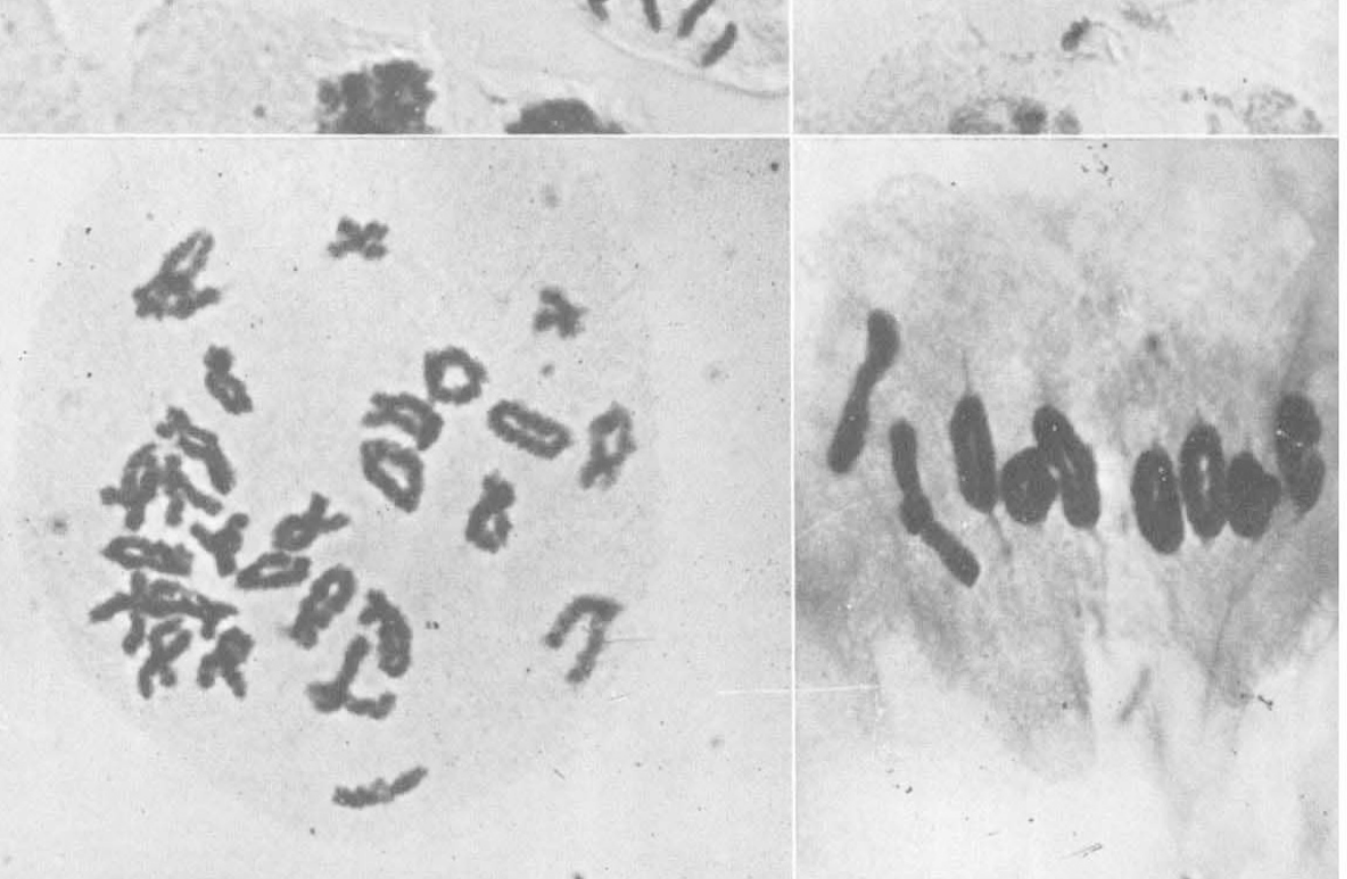

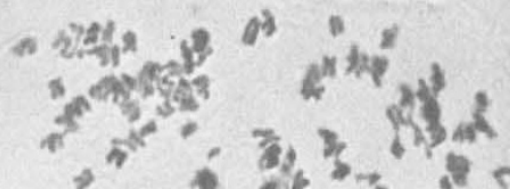

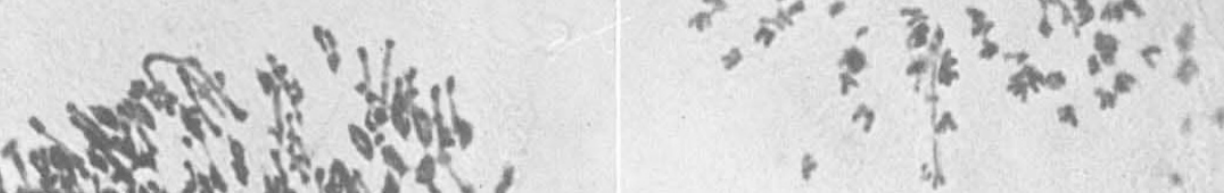
1.6. bonitong

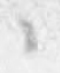

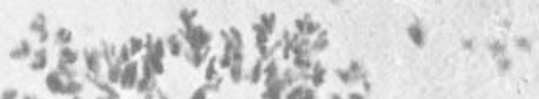

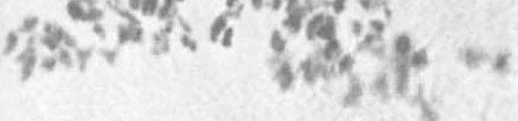


2. There are two main centres of diversity in the genus, one in China and Japan, and the other at the Western end of the Mediterranean. Most Mediterranean species are annuals and diploid, the Oriental ones chiefly perennial and polyploid. Arctic species are entirely polyploid.

3. Eight species show varying degrees of polyploidy. In one of these, $C$. frutescens, only the sterile triploid form has been examined. C. maximum varies, in its garden forms, between 85 and I7 I chromosomes.

4. Increase in chromosome number in the polyploid series is accompanied by decrease in chromosome size.

5. Accessory heterochromatic iso-chromosomes occur in two species. These undergo misdivision and give telocentrics.

6. Meiosis is regular in the botanic garden species studied except C. atratum. There is little loss of unpaired chromosomes in the higher polyploids owing to the small size of the pollen mother cell relative to the nucleus.

\section{REFERENCES}

DARLINGTON, G. D., AND LA GouR, L. F. 1950. Hybridity selection in Campanula. Heredity, 4, 21 7-248.

DARLINGTON, C. D., AND THOMAS, P. T. 1941. Morbid mitosis and the activity of inert chromosomes in Sorghum. P.R.S., B., $130,127-150$.

MÜNTZING, A. 1944. Cytological studies of extra fragment chromosomes in Rye. I. Iso-fragments produced by misdivision. Hereditas, 30, 231-248.

MüNTZING, A. 1948. Accessory chromosomes in Poa alpina. Heredity, 2, 49-6I.

o'marA, J. G. 1948. Acetic acid methods for chromosome studies at prophase and metaphase in meristems. Stain Tech., 23, $201-204$.

shimotomal, N. 1931. Bastardierungsversuche bei Chrysanthemum. I. 7. Sci. Hiroshima Univ., Ser. B. Div. 2., I, 37-54.

shimotomai, N. 1932. Bastardierungsversuche bei Chrysanthemum. II. F. Sci. Hiroshima Univ., Ser. B. Div. 2., I, I1 7-120.

shimotomai, N. 1933. Zur Karyogenetik der Gattung Chrysanthemum. F. Sci. Hiroshima Univ., Ser. B. Div. 2., 2, 1-1001

shimotomal, N. 1937a. Uber eine triploide Pflanze von Chrysanthemum. Cytologia, Fujii Jubilee Volume, $845-849$.

shimoтомal, N. 1937b. Chromosomenzahlen bei einigen Arten von Chrysanthemum. Z.I.A.V., 74, 30-33.

stern, F. c. 1949. Chromosome numbers and taxonomy. Proc. Linn. Soc., Lond., $x 6 x$, 119-128.

SUGIURA, T. 1937. Studies on the chromosome numbers of higher plants with special reference to Cytokinesis II. Cytologia, Fujii Jubilee Volume, 845-849.

таkemoto, T. 1935. Über die Morphologie der Chromosomen bei einer Art und zwei Bastarden von Chrysanthemum. 7. Sci. Hiroshima Univ., Ser. B. Div. 2., 3, 205-2.09. upcort, м. 1937. The external mechanics of the chromosomes. VI. The behaviour of the centromere at meiosis. P.R.S., B., I24, 336-361. 